\title{
CORRECTION
}

\section{Correction to: Understanding gender disparities in outcomes after sepsis}

\author{
M. Elizabeth Wilcox ${ }^{1,2^{*}}$ (D, John P. Donnelly ${ }^{3,4}$ and Nazir I. Lone $e^{5,6}$
}

(0) 2020 Springer-Verlag GmbH Germany, part of Springer Nature

\section{Correction to: Intensive Care Med}

https://doi.org/10.1007/s00134-020-05961-3

The original version of this article unfortunately contained a mistake. There was an error in Fig. 1 . The correct Fig. 1 can be found below. We apologize for the mistake.

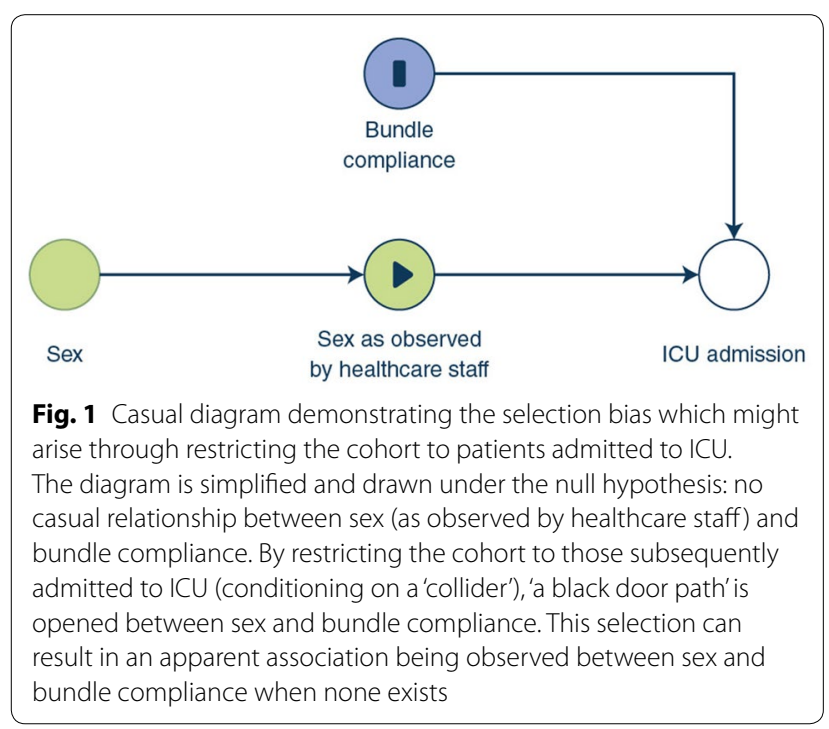

*Correspondence: elizabeth.wilcox@utoronto.ca

${ }^{1}$ Interdepartmental Division of Critical Care Medicine, University

of Toronto, Toronto, ON, Canada

Full author information is available at the end of the article

The original article can be found online at https://doi.org/10.1007/s0013 4-020-05961-3.

\begin{abstract}
Author details
${ }^{1}$ Interdepartmental Division of Critical Care Medicine, University of Toronto, Toronto, ON, Canada. ${ }^{2}$ Division of Respirology, Department of Medicine, University Health Network and Mount Sinai Hospital, Toronto, ON, Canada. ${ }^{3}$ Department of Learning Health Sciences, University of Michigan, Ann Arbor, MI, USA. ${ }^{4}$ Institute for Healthcare Policy \& Innovation, University of Michigan, Ann Arbor, MI, USA. ${ }^{5}$ Usher Institute, University of Edinburgh, Edinburgh, UK. ${ }^{6}$ Department of Critical Care, Royal Infirmary of Edinburgh, NHS Lothian, Edinburgh, UK.
\end{abstract}

\section{Publisher's Note}

Springer Nature remains neutral with regard to jurisdictional claims in published maps and institutional affiliations.

Published online: 13 March 2020

\section{Springer}

